\title{
Thansforaminal endoscopic decompression of a postoperative dislocated bone fragment after a 2-level lumbar total disc replacement: case report
}

\author{
Ralf Wagner, MD, ${ }^{1}$ Menno Iprenburg, $M D,{ }^{2}$ and Albert E. Telfeian, MD, $\mathrm{PhD}^{3}$ \\ ${ }^{1}$ Ligamenta Spine Centre, Frankfurt am Main, Germany; ${ }^{2}$ Spine Clinic Iprenburg, Veenhuizen, The Netherlands; and ${ }^{3}$ Department \\ of Neurosurgery, Rhode Island Hospital, The Warren Alpert Medical School of Brown University, Providence, Rhode Island \\ The proposed advantages of total disc replacement (TDR) over fusion in the lumbar spine are the preservation of motion \\ and the avoidance of adjacent-level disease. One of the complications inherent in TDR is the possibility of vertebral \\ body fracture due to trauma or a malpositioned implant. The resulting dilemma is that posterior decompression of the \\ displaced bone fragment could then have a destabilizing effect and possibly require fusion, thus obviating the benefit of \\ an arthroplasty procedure. In this study, the authors describe the technical considerations and feasibility of the treatment \\ of a postoperative L-5 paresis that resulted from a dislocated bone fragment at L4-5 during a 2-level lumbar TDR. \\ http://thejns.org/doi/abs/10.3171/2015.11.FOCUS15492
}

KEY WORDS endoscopic discectomy; minimally invasive; transforaminal; total disc replacement

$\mathrm{L}$ UMBAR artificial total disc replacement (TDR) (also known as lumbar intervertebral disc prosthesis or lumbar total disc arthroplasty) is considered for the treatment of symptomatic lumbosacral degenerative disc disease in skeletally mature patients in whom conservative treatment has failed and who do not have significant joint degeneration, osteopenia/osteoporosis, or severe instability. ${ }^{2,22,23}$ Early complications of the procedure include problems with initial implant positioning or, in rare cases, the implant can fracture the vertebra upon insertion or the vertebra can fracture during the postoperative period. . $, 5,7,18,19,22,23$ If this occurs, revision surgery with possible conversion to a spinal fusion may be needed., , $, 6,8,10-12^{2}$

The performance of lumbar TDR underwent a surge in the US and then a decline, due mostly to problems with insurance approval. The US FDA has only approved implantation of lumbar TDR for 1-level cases between L-3 and S-1.22 Patients in the US seeking multilevel lumbar TDR leave the country and usually travel to Germany (where the first Charité artificial disc was implanted in 1984) ${ }^{9}$ for treatment in which a 1- to 4-level lumbar TDR is performed.

Transforaminal lumbar endoscopic surgery is a minimally invasive surgical approach to lumbar spine pathology that has been previously described as a novel "rescue" surgery for patients with persistent lumbar nerve root compression after transforaminal lumbar interbody fusion, ${ }^{14,15}$ lumbar instrumented fusion, ${ }^{16}$ and other lumbar decompressive surgery. ${ }^{21}$ Herein, we present the case of a patient with an acute L-5 paresis after an L4-S1 TDR, complicated by a retropulsed bone fragment in the neural foramina and treated successfully with transforaminal endoscopic surgery.

\section{Case Report}

History and Presentation

A 40-year-old woman presented with a $>3$-year history of low-back pain despite conservative treatment with physical therapy and interventional pain management. Preoperative lumbar MRI demonstrated a decreased T2 signal at the L4-5 and L5-S1 levels, with only mild loss of disc height. The preoperative visual analog scale back score was 7/10, with no symptoms radiating to the legs and no deficits on neurological examination. She underwent an L4-S1 2-level TDR (LP-ESP; FH Orthopedics). Three hours after the surgery, she developed a right foot drop. An emergency lumbar CT scan was performed, revealing a slightly lateralized position of the L4 -5 implant and a large bone fragment of the inferior posterior L-4 vertebral body in the right neural foramen (Fig. 1). 

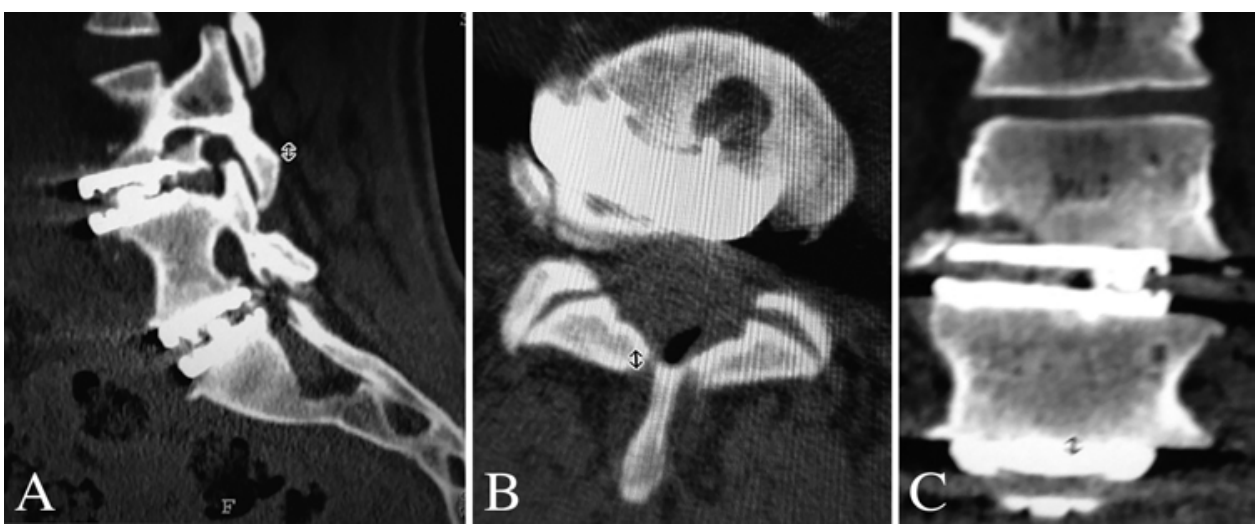

FIG. 1. CT scans obtained after L4-S1 TDR. Sagittal CT reconstruction shows a fragment of the inferior portion of the body of L-4 retropulsed into the right neural foramen (A). Axial CT shows the TDR implant positioned slightly to the right of L4-5 (B). Coronal CT reconstruction shows slight misalignment of the L4-5 TDR implant and the bone fracture of the inferior portion of the L-4 vertebral body (C).

\section{Operation}

For the surgery to decompress the retropulsed bone fragment in the right L4-5 foramen, general anesthesia was induced and the patient was placed prone on the Wilson frame. The joimax TESSYS endoscopic system was used for the procedure. Percutaneous entry was established, entering through the skin $11 \mathrm{~cm}$ lateral to the midline. Using intermittent fluoroscopic guidance, alternating between lateral and anteroposterior views, a 25$\mathrm{cm}$ 18-gauge needle was advanced and placed in the disc space through Kambin's triangle, between the exiting and traversing nerves. An anteroposterior fluoroscopic view was used to ensure that the disc space was entered before the needle was inserted beyond the medial wall of the pedicle.

Sequential reamers were used to enlarge the neural foramen by removing the ventral aspect of the superior articulating process (Fig. 2). Resection of the bone fragment and decompression of the neural foramen were then performed. Figure $3 \mathrm{~A}$ and Video 1 depict identification of the bone fragment. Figure $3 \mathrm{~B}$ and Video 2 depict seg- mentation of the bone fragment with the diamond drill Figure 3C and Video 3 depict resection of the bone fragment with the down-biting grasper. Figure 3D and Video 4 depict resection of the posterior ligament with the grasper and exposure of the TDR implant. Figure 3E and Video 5 depict the endoscopic view of the neural foramen after decompression; the exiting and traversing nerve roots can be visualized. The disc and bone fragments removed are shown in Fig. 4.

VIDEO 1. Clip showing identification of the bone fragment. Copyright Albert E. Telfeian. Published with permission. Click here to view.

VIDEO 2. Clip showing segmentation of the bone fragment with the diamond drill. Copyright Albert E. Telfeian. Published with permission. Click here to view.

VIDEO 3. Clip showing resection of the bone fragment with the down-biting grasper. Copyright Albert E. Telfeian. Published with permission. Click here to view.

VIDEO 4. Clip showing resection of the posterior ligament with the grasper and exposure of the TDR implant. Copyright Albert E. Telfeian. Published with permission. Click here to view.

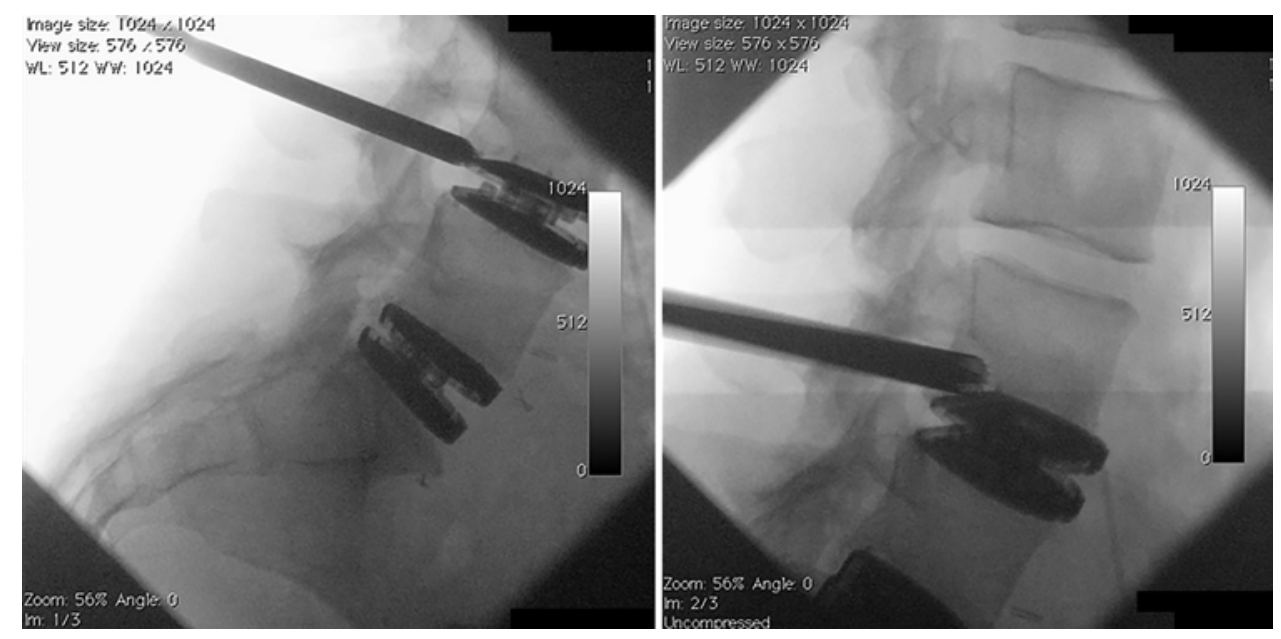

FIG. 2. Lateral fluoroscopic radiographic views of access to the right L4-5 neural foramen. The Seldinger approach was used, with sequential dilators placed down to the foramen (left). Sequential reamers were used to remove a portion of the ventral aspect of the superior articulating process of L-5 to allow endoscopic visualization of the right L4-5 foramen (right). 

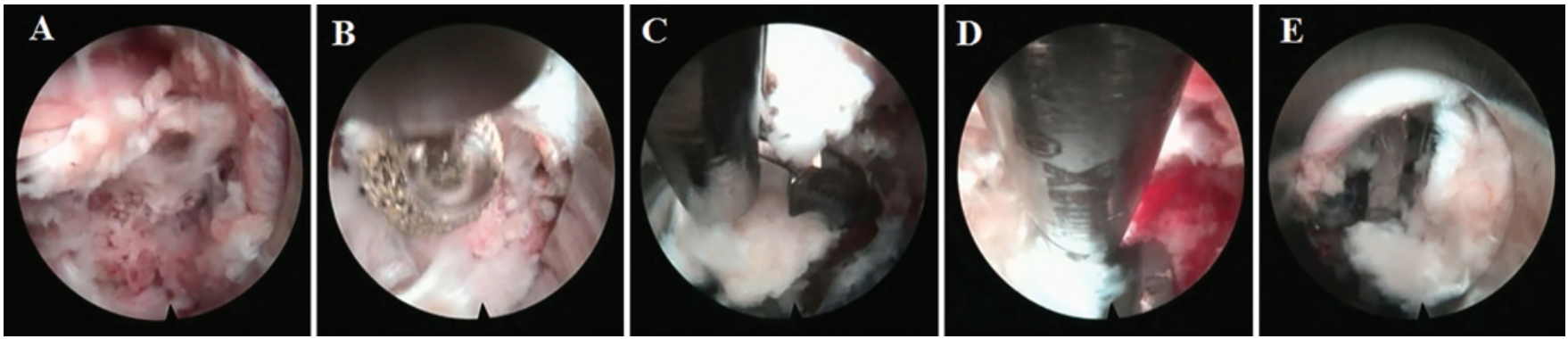

FIG. 3. Endoscopic resection of the retropulsed bone fragment and decompression of the neural foramen. A: Identification of the bone fragment. (See also Video 1.) B: Segmentation of the bone fragment with the diamond drill. (See also Video 2.) C: Resection of the bone fragment with the down-biting grasper. (See also Video 3.) D: Resection of the posterior ligament with the grasper and exposure of the TDR implant. (See also Video 4.) E: Endoscopic view of the neural foramen after decompression; the exiting and traversing nerve roots can be visualized. (See also Video 5.)

VIDEO 5. Clip showing the endoscopic view of the neural foramen after decompression; the exiting and traversing nerve roots can be visualized. Copyright Albert E. Telfeian. Published with permission. Click here to view.

\section{Postoperative Course}

At the termination of the procedure, the working channel and scope were removed, pressure was held on the 5 -mm incision for 5 minutes, and the wound was closed with a single interrupted suture. Immediately after the procedure, the patient's foot dorsiflexion paresis improved and her foot strength was completely normal by the next day. One year after her 2-level TDR, she described her result as "excellent."

\section{Discussion}

The most frequent early complications associated with lumbar TDR include device anterior migration, sizing and malpositioning errors, and posterior element fracture. Together, these occur with an incidence between $1 \%$ and $2 \% .1,5,7,18,19$ Other studies have shown that endoscopic spine surgery is an effective procedure for treating multiple pathologies in the lumbar spine, including lateral, paracentral, central, extruded, and even contralateral herniated discs, as well as lateral recess stenosis. ${ }^{3,13,17,20}$ The success of treating lumbar radicular symptoms in the setting of spinal instrumentation has also recently been published. ${ }^{14-16}$

Herein, we describe the first published case of a transforaminal endoscopic procedure used to successfully treat the complication of a vertebral body fracture after lumbar TDR, resulting in symptomatic foraminal compromise. The technology and access route involved in transforaminal endoscopic surgery are ideally suited to treat this particular complication, which is inherent to TDR device placement. The point of TDR is to preserve spinal motion while eliminating discogenic back pain. Preserved spinal stability with intact posterior spinal elements is considered necessary for successful TDR. Unfortunately, surgical treatment for complications of TDR, whether they are through an anterior, posterior, or extreme lateral approach, usually result in a fusion of the previously treated arthroplasty level. .,6,8,10-12 $^{-12}$

The transforaminal route and minimally invasive endoscopic technique offer the advantage of a route and access that allows the foramen to be decompressed (even if the compressive element is a rather large bone fragment) without destabilizing the motion segment. The surgical instruments available today for endoscopic spine surgery (i.e., reamers, drills, graspers, electrocautery, ball probes, and nerve hooks) do, for the most part, mirror those available for open spine surgical procedures. The case presented here is intended to provide the community of spine surgeons with increased awareness of the possibilities of endoscopic approaches, not just for primary pathology but also for so-called rescue or revision surgical approaches.

Although more and more spine pathologies are being treated with endoscopic minimally invasive techniques, it is worth mentioning the potential pitfalls of endoscopic spine surgery, which include a difficult learning curve, small instruments and drills, and the challenges of targeting the pathology. This single case report represents a successful acute surgical rescue procedure for a TDR complication. However, a larger series would have to be examined to address long-term sequelae after such a procedure. These could include restenosis, possible heterotopic ossification secondary to drilling, and impact on mechanical function of the arthroplasty prosthesis.

Most of the major health insurance carriers in the US (including UnitedHealth, Aetna, Humana, and most Blue Cross Blue Shield affiliates) do not provide coverage for single-level lumbar TDR. The most common explanation

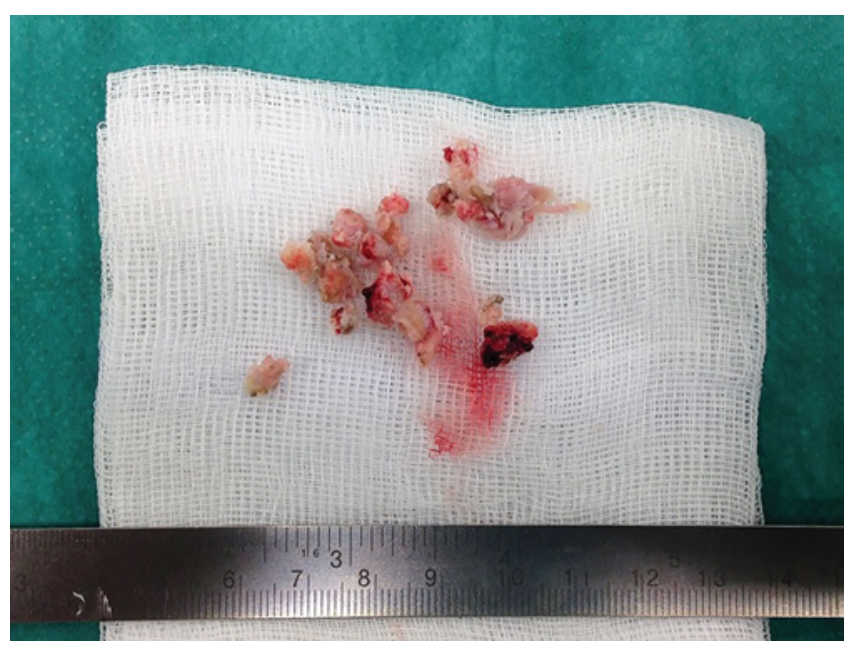

FIG. 4. Bone and disc fragments that were removed in the endoscopic decompression of the right $L 4-5$ foramen. 
is that the technology is considered investigational, despite the fact that studies involving 1 level have demonstrated decreased adjacent-level disease, minimal componentwear issues, and lower revision rates than fusion. Patients seeking a lumbar TDR option travel abroad (often to Germany), seeking evaluation and possible surgical treatment. Spine surgeons worldwide should be prepared to treat the complications that patients may suffer following lumbar TDR. In this study, we present a unique, minimally invasive, nondestabilizing treatment for a complication that could be recognized early or late after a lumbar TDR.

\section{References}

1. Blumenthal SL, Guyer RD, Geisler FH, McAfee PC, Regan JJ: The first 18 months following food and drug administration approval of lumbar total disc replacement in the United States: reported adverse events outside an investigational device exemption study environment. SAS J 1:8-11, 2007

2. Büttner-Janz K, Guyer RD, Ohnmeiss DD: Indications for lumbar total disc replacement: selecting the right patient with the right indication for the right total disc. Int J Spine Surg 8:10, 2014

3. Choi G, Lee SH, Lokhande P, Kong BJ, Shim CS, Jung B, et al: Percutaneous endoscopic approach for highly migrated intracanal disc herniations by foraminoplastic technique using rigid working channel endoscope. Spine (Phila Pa 1976) 33:E508-E515, 2008

4. de Maat GH, Punt IM, van Rhijn LW, Schurink GW, van Ooij A: Removal of the Charité lumbar artificial disc prosthesis: surgical technique. J Spinal Disord Tech 22:334-339, 2009

5. Geisler FH, Blumenthal SL, Guyer RD, McAfee PC, Regan JJ, Johnson JP, et al: Neurological complications of lumbar artificial disc replacement and comparison of clinical results with those related to lumbar arthrodesis in the literature: results of a multicenter, prospective, randomized investigational device exemption study of Charité intervertebral disc. Invited submission from the Joint Section Meeting on Disorders of the Spine and Peripheral Nerves, March 2004. J Neurosurg Spine 1:143-154, 2004

6. Gerometta A, Rodriguez Olaverri JC, Bittan F: Infection and revision strategies in total disc arthroplasty. Int Orthop 36:471-474, 2012

7. Holt RT, Majd ME, Isaza JE, Blumenthal SL, McAfee PC, Guyer RD, et al: Complications of lumbar artificial disc replacement compared to fusion: Results from the prospective, randomized, multicenter US Food and Drug Administration Investigational Device Exemption Study of the Charité artificial disc. SAS J 1:20-27, 2007

8. Leary SP, Regan JJ, Lanman TH, Wagner WH: Revision and explantation strategies involving the CHARITÉ lumbar artificial disc replacement. Spine (Phila Pa 1976) 32:1001-1011, 2007

9. Link HD: History, design and biomechanics of the LINK SB Charité artificial disc. Eur Spine J 11 (Suppl 2):S98-S105, 2002

10. McAfee PC, Salari B, Saiedy S: Reoperations and complications of failed lumbar total disk replacement. Semin Spine Surg 24:37-42, 2012

11. Patel AA, Brodke DS, Pimenta L, Bono CM, Hilibrand AS, Harrop JS, et al: Revision strategies in lumbar total disc arthroplasty. Spine (Phila Pa 1976) 33:1276-1283, 2008

12. Pimenta L, Díaz RC, Guerrero LG: Charité lumbar artificial disc retrieval: use of a lateral minimally invasive technique. Technical note. J Neurosurg Spine 5:556-561, 2006

13. Ruetten S, Komp M, Merk H, Godolias G: Surgical treatment for lumbar lateral recess stenosis with the full-endoscopic interlaminar approach versus conventional microsurgical technique: a prospective, randomized, controlled study. J Neurosurg Spine 10:476-485, 2009

14. Telfeian AE: Endoscopic foraminotomy for recurrent lumbar radiculopathy after TLIF: Technical report. Surg Neurol Int 6:62, 2015

15. Telfeian AE: Transforaminal endoscopic solution to disk reherniation post-mini-TLIF: case report. Clin Neurol Neurosurg 131:69-71, 2015

16. Telfeian AE, Jasper GP, Francisco GM: Transforaminal endoscopic treatment of lumbar radiculopathy after instrumented lumbar spine fusion. Pain Physician 18:179-184, 2015

17. Thomé C, Barth M, Scharf J, Schmiedek P: Outcome after lumbar sequestrectomy compared with microdiscectomy: a prospective randomized study. J Neurosurg Spine 2:271278, 2005

18. van Ooij A, Oner FC, Verbout AJ: Complications of artificial disc replacement: a report of 27 patients with the SB Charité disc. J Spinal Disord Tech 16:369-383, 2003

19. Wei J, Song Y, Sun L, Lv C: Comparison of artificial total disc replacement versus fusion for lumbar degenerative disc disease: a meta-analysis of randomized controlled trials. Int Orthop 37:1315-1325, 2013

20. Yeom KS, Choi YS: Full endoscopic contralateral transforaminal discectomy for distally migrated lumbar disc herniation. J Orthop Sci 16:263-269, 2011

21. Yeung A, Gore S: Endoscopic foraminal decompression for failed back surgery syndrome under local anesthesia. Int J Spine Surg 8:8, 2014

22. Zigler JE, Delamarter RB: Five-year results of the prospective, randomized, multicenter, Food and Drug Administration investigational device exemption study of the ProDisc-L total disc replacement versus circumferential arthrodesis for the treatment of single-level degenerative disc disease. $\mathbf{J}$ Neurosurg Spine 17:493-501, 2012

23. Zigler J, Delamarter R, Spivak JM, Linovitz RJ, Danielson GO III, Haider TT, et al: Results of the prospective, randomized, multicenter Food and Drug Administration investigational device exemption study of the ProDisc-L total disc replacement versus circumferential fusion for the treatment of 1-level degenerative disc disease. Spine (Phila Pa 1976) 32:1155-1163, 2007

\section{Disclosures}

Dr. Iprenburg received payments from joimax for teaching.

\section{Author Contributions}

Conception and design: all authors. Acquisition of data: Wagner. Analysis and interpretation of data: all authors. Drafting the article: all authors. Critically revising the article: all authors. Reviewed submitted version of manuscript: all authors. Approved the final version of the manuscript on behalf of all authors: Telfeian. Administrative/technical/material support: all authors. Study supervision: all authors.

\section{Supplemental Information Videos}

Video 1. https://vimeo.com/148102872.

Video 2. https://vimeo.com/148102874.

Video 3. https://vimeo.com/148102873.

Video 4 . https://vimeo.com/148102875.

Video 5. https://vimeo.com/148102871.

\section{Correspondence}

Albert Telfeian, Department of Neurosurgery, Rhode Island Hospital, 593 Eddy St., Providence, RI 02903. email: atelfeian@ lifespan.org. 